\title{
Geometria e Educação Infantil: Entre a Pesquisa, o Desenvolvimento de Materiais de Ensino e a Formação Continuada de Professoras ${ }^{1}$
}

\section{Geometry and Early Childhood Education: Between Research, the Development Of Teaching Materials and the Continuing Education of Teachers}

\author{
Regina Maria Pavanello*a; Leila Pessôa da Costa ${ }^{\mathrm{b}}$; Sandra Regina D’Antonio Verrengia ${ }^{\mathrm{b}}$ \\ ${ }^{a}$ Universidade Estadual do Paraná, Campus de Campo Mourão. PR, Brasil. \\ bUniversidade Estadual de Maringá. PR, Brasil. \\ *E-mail rmpavanello@gmail.com.
}

\begin{abstract}
Resumo
Pesquisas apontam o descaso não só com o ensino de geometria, mas também com a falta de preparo do professor da Educação Infantil (EI) para trabalha-lo em sala de aula. Situação essa que causa sérios prejuízos à formação dos indivíduos, visto que o aluno passa, gradativamente, por um processo de sucessivas elaborações que parte do real e tático para, aos poucos, tornar-se independente de objetos e desenhos para ser capaz de visualizá-la no campo das ideias, desenvolvimento essencial a ser promovido pela escola. Este texto analisa três tarefas propostas a um grupo de professoras/educadoras de duas creches/centros de Educação Infantil de uma cidade situada na região noroeste do Estado do Paraná. Essas tarefas fazem parte de um projeto de pesquisa destinado a formação na docência para o ensino de geometria e o desenvolvimento das capacidades espaciais. Apoiado na Engenharia Didática e na dialogicidade freireana, considera que a construção dos conhecimentos emerge das experiências e práticas das crianças sobre si, sobre os objetos e sobre o meio que as cerca, bem como a importância do processo de ensino institucionalizado (ou de escolarização) para que essa aprendizagem se efetive. Constatamos a importância da metodologia utilizada não só para as "realizações didáticas" como também para a instituição dos professores como sujeitos de seu processo de aprendizagem e de seu desenvolvimento profissional bem como de ser ela uma forma profícua para a formação na docência.
\end{abstract}

Palavras-chave: Educação Infantil. Geometria. Capacidades Espaciais. Formação na Docência. Engenharia Didática.

\begin{abstract}
Research points to the neglect not only of teaching geometry, but also of the lack of preparation of the Early Childhood Education (EI) teacher to work in the classroom. This situation causes serious damage to the training of individuals, since the student gradually goes through a process of successive elaboration that starts from the real and tactical, to gradually become independent of objects and drawings to be able to visualize it in the field of ideas, an essential development to be promoted by the school. This text analyzes three tasks proposed to a group of teachers/educators from two kindergartens/centers of Early Childhood Education in a city located in the northwestern region of Paraná State. These tasks are part of a research project aimed at the teaching of geometry and the development of spatial capabilities. Supported by Didactic Engineering and Freirean dialogue, it considers that the construction of knowledge emerge from the experiences and practices of children about themselves, about the objects and the environment surrounding them, as well as the importance of the process of institutionalized teaching (or schooling) for this learning to be effective. We noted the importance of the methodology used not only for the "didactic achievements" but also for the institution of teachers as subjects of their learning process and their professional development as well as of being a fruitful form for training in teaching.
\end{abstract}

Keywords: Early Childhood Education. Geometry. Spatial Skills. Teaching Training. Didactic Engineering.

\section{Introdução}

O mapeamento das pesquisas sobre o ensino da geometria no Brasil realizado por Sena e Dorneles (2013) mostrou não só o descaso com esse tema, mas também a falta de preparo do professor dos anos iniciais do Ensino Fundamental (EF) para trabalha-lo em sala de aula.

Esse descaso pode causar sérios prejuízos à formação dos indivíduos, visto ser na educação básica que o aluno passa, gradativamente, "da geometria tátil e real para a formalização desta" (Montoio \& Leivas, 2012, p.33), tornando-se independente de objetos e desenhos para ser capaz de visualizá-la no campo das ideias.

Nessa concepção o processo de formação indica a necessidade de o ensino de geometria começar já na Educação Infantil (EI), prolongando-se posteriormente para o EF por meio de explorações intuitivas que possibilitem às crianças o estabelecimento de conhecimentos indispensáveis a uma posterior sistematização com vistas à construção formal de tais conceitos ao final da Educação Básica (EB).

Contudo, se os professores que trabalham tanto na EI quanto nos anos iniciais do EF não tiverem o preparo necessário em relação a esse tema matemático, como podem responder a essa necessidade?

Foi pensando nesta questão que desenvolvemos, no Grupo de Estudos e Pesquisas em Matemática Escolar (GEPEME/ UEM), uma pesquisa intitulada "Elaboração de materiais para a Educação Infantil e anos iniciais do Ensino Fundamental

1 Nos referimos no feminino às profissionais que participaram desse projeto por serem todas deste sexo 
com vistas ao desenvolvimento das Capacidades Espaciais em Geometria", submetida e aprovada pelo comitê de ética da Universidade Estadual de Maringá (1.760.158). A metodologia utilizada voltou-se ainda para o exame das possibilidades de formação de professores que atuam na EI e nos Anos Iniciais do EF a partir da organização e aplicação, por eles, de tarefas que permitissem a exploração do conhecimento geométrico por ambos os segmentos.

Neste texto, compartilhamos o trabalho realizado no âmbito da EI que foi feito em primeiro lugar, devido ao fato de este período da escolarização ter sido incluído pela Lei $n^{\circ} 12796 / 2013$ que alterou a Lei de Diretrizes e Bases da Educação Nacional (Lei n. 9394, 1996) incluindo a EI como primeira etapa da EB.

\section{A Educação Infantil e os Conceitos Geométricos}

Estudos, como o de Pacheco e Vasconcelos (2016), destacam que a estruturação espacial pela criança se inicia já nos primeiros meses de vida, em paralelo às construções mentais, embora essa estruturação já se inicie no útero materno.

Para os autores citados, o primeiro espaço que a criança vivencia é postural e orgânico, ou seja, se inicia com seu corpo e "somente depois é que ela vai diferenciar outros corpos, diferentes do seu, e estabelecer relação de longe/perto, maior/menor, na frente/atrás, igual/diferente, etc." (Pacheco \& Vasconcelos, 2016, p. 4).

Esse foi um dos pontos de referência apresentado nos Parâmetros Curriculares Nacionais - PCNs (Brasil, 1997) quando afirmaram que, para se orientar a criança é incapaz de considerar qualquer outro elemento, que não o seu próprio corpo, como ponto de referência. Aos poucos, ela toma consciência de que os diferentes aspectos sob os quais os objetos se apresentam para ela são perfis de uma mesma coisa, ou seja, ela gradualmente toma consciência dos movimentos de seu próprio corpo, de seu deslocamento (Brasil, 1997, p.125).

A Base Nacional Comum Curricular (Brasil, 2018), atual referência para a educação brasileira, assinala também que:

Com o corpo (por meio dos sentidos, gestos, movimentos impulsivos ou intencionais, coordenados ou espontâneos), as crianças, desde cedo, exploram o mundo, o espaço e os objetos do seu entorno, estabelecem relações, expressam-se, brincam e produzem conhecimentos sobre si, sobre o outro, sobre o universo social e cultural, tornando-se, progressivamente, conscientes dessa corporeidade (Brasil, 2018, pp. 42-43).

A conquista da compreensão do espaço pela criança acontece em dois planos: o da percepção - de si, dos outros e do ambiente - e o da representação, ou seja, o que é apreendido e o que é representado do espaço vivido por ela.

Oliveira (2005, p. 110) esclarece a diferença entre a percepção e a representação dizendo que, enquanto a percepção e o conhecimento dos objetos resultam de um contato direto com estes, a representação implica na capacidade de evocar os objetos em sua ausência.

Para a autora, a representação prolonga a percepção introduzindo um elemento novo, um sistema de significações que comporta diferenciação entre o significante e o significado, ou ainda, sobre a imagem e o pensamento. Segundo ela, este espaço topológico se apresenta para a criança como uma reunião de fragmentos distintos no qual os objetos não se relacionam uns com os outros formando um conjunto.

Estudos como o de Oliveira (2005) indicam que as primeiras condutas das crianças são, portanto, de natureza topológica, seguidas, posteriormente, pelas de natureza projetiva e euclidiana. Para que ela disponha de estruturas espaciais acabadas é preciso que considere as distâncias objetivas e os pontos de vista possíveis coordenando esses espaços parcelados em um espaço total (Oliveira, 2005, p.116).

A autora indica que, do ponto vista topológico, a criança concebe esses espaços a partir da construção de dois sistemas diferentes e complementares, um dos quais é o de coordenadas, fonte do espaço euclidiano, que lhe permite situar os objetos entre si, e, o outro, o das perspectivas, que considera diferentes pontos de vista, reais ou possíveis (Oliveira, 2005).

A representação espacial é, portanto, algo complexo

[...] fruto de um longo e laborioso trabalho da inteligência, que tem início nas ações do recém-nascido (esquemas sensório-motores) que irá ser reconstruído no plano da representação, passando por um período intuitivo necessário e preparatório de reconstrução do que foi realizado no sensório-motor, e que irá concretizar-se com as operações formais (Kobayashi, 2001, p.175).

Até os dois anos há um extraordinário desenvolvimento mental que Piaget (1999, p. 19) vê como decisivo para todo o curso da evolução psíquica, uma vez que representa a conquista, a partir da percepção e dos movimentos, de todo o universo prático que cerca a criança. $\mathrm{O}$ autor caracteriza ainda a construção do pensamento infantil como uma forma de inteligência prática gerada pela manipulação de objetos e do meio quando a criança explora seu próprio corpo, se conhece, sente emoções e é estimulada pelo ambiente social para desenvolver a base do seu autoconceito.

É, portanto, um período complexo do ponto de vista do desenvolvimento, por ser nele que ocorre a organização psicológica básica no que diz respeito aos aspectos perceptivo, motor, intelectual, afetivo e social (Coutinho, 1976). É nele que a criança aprimora seus movimentos, adquire habilidades e desenvolve comportamentos que lhe permitirão organizar a construção do espaço prático, da causalidade e a objetivação das séries temporais, dos esquemas representativos e simbólicos (Faria, 1998).

Ainda, para La Taille (2003), a criança desenvolve recursos pessoais para resolver uma série de situações por meio de uma inteligência explícita, que a fará se perceber como participante do mundo, situando a si mesma como um objeto específico, agente e paciente dos eventos que nele ocorrem. 
Em relação à construção de conceitos geométricos, as pesquisas de Dina Van Hiele-Geldof (1957) e Pierre Van Hiele $(1957,1986)$ os levaram a considerar a existência de diferentes níveis de pensamento e, portanto, diferentes fases na sua aprendizagem. Os autores estabeleceram cinco níveis, dos quais os iniciais, que se referem às crianças da EI, seriam os seguintes:

Nível 0 - Pré-reconhecimento - os alunos neste nível dão atenção apenas a parte das características visuais de uma figura, são incapazes de identificar muitas figuras comuns Nível 1 - Visual - os alunos identificam, descrevem e raciocinam acerca das figuras e outras configurações geométricas de acordo com a sua aparência como um todo visual. Os seus raciocínios são dominados pela percepção visual e imagética e não por uma análise das propriedades geométricas. Quando identificam figuras, os alunos usam muitas vezes protótipos visuais, por exemplo, dizendo que uma figura é um retângulo porque "se parece com uma porta" (Breda et al, 201, p.18).

A construção dos conceitos explorados nessa pesquisa, tendo como referência o trabalho dos Van Hiele, nos mostrou a necessidade de definir um nível anterior ao proposto por estes pesquisadores (pré-reconhecimento ou nível 0 ), o qual denominamos de nível 00 , ou o nível das experiências geométricas.

Para nós, o nível 00 seria aquele no qual a criança reconhece aos pouco seu corpo e, a partir desse reconhecimento, passa a diferenciar outros corpos, bem como a estabelecer relações topológicas elementares de localização (longe/perto), sentido (frente/atrás), direção (esquerda/direita); comprimento (maior/menor), semelhança (igual/diferente), etc., mediante as relações que estabelece com os objetos e o meio a sua volta, pois é desde cedo, a partir das experiências geométricas, que os conceitos, bem como o raciocínio espacial, vão sendo desenvolvidos.

Conforme apontam Mendes e Delgado (2008), desde cedo alguns conceitos são desenvolvidos, tal como o raciocínio espacial. Assim,

Ainda bebés, não só revelam curiosidade em "olhar" o espaço que as rodeia, como, também, interagem com ele, tentando, por exemplo, alcançar, atirar e empurrar objectos. Durante estas experiências, vão processando ideias sobre as formas e o espaço. Estas ideias, ainda muito rudimentares, constituem já a base para o conhecimento geométrico e o raciocínio espacial que deverá ser desenvolvido ao longo dos anos seguintes (Mendes \& Delgado, 2008, p.11).

Assim sendo, ao pensarmos na aprendizagem da matemática, e em especial a da geometria, é importante ressaltar que, na EI, a construção dos conhecimentos emergirá das experiências e práticas das crianças sobre si, sobre os objetos e sobre o meio que as cerca. E, embora a familiaridade da criança com os conhecimentos geométricos ocorra antes mesmo do seu ingresso na EI, é no processo de ensino institucionalizado (ou de escolarização) que as tarefas são organizadas para que essa aprendizagem se efetive.

\section{Do Procedimento Metodológico do Projeto de Pesquisa}

Considerando a importância do ensino de Geometria para o desenvolvimento do aluno e a falta de formação do professor que atua na Educação Infantil em relação a essa área de conhecimento, as pesquisadoras do GEPEME/UEM propuseram o desenvolvimento de uma pesquisa a partir da qual se pudesse investigar as possibilidades de um processo de formação continuada de professores que atuam nessa faixa da escolarização a partir da produção e da testagem de materiais destinados ao desenvolvimento das Capacidades Espaciais em Geometria na Educação Infantil.

As tarefas relacionadas aos temas direcionados para a Educação Infantil foram aplicadas em duas creches de uma cidade situada na região noroeste do Estado do Paraná. A metodologia adotada nessa pesquisa - qualitativa de natureza experimental - se apoiava nos princípios da Engenharia Didática que se caracteriza:

por um esquema experimental baseado em "realizações didáticas" em sala de aula, isto é, na concepção, realização, observação e análise de sessões de ensino. Caracteriza se também como pesquisa experimental pelo registro em que se situa e modo de validação que lhe são associados: a comparação entre análise a priori e análise a posteriori. Tal tipo de validação é uma das singularidades dessa metodologia, por ser feita internamente, sem a necessidade de aplicação de um pré-teste ou de um pós-teste (Almouloud \& Coutinho, 2008, p. 66).

$\mathrm{Na}$ análise preliminar pesquisamos na literatura o que as pesquisas dizem sobre o desenvolvimento das Capacidades Espaciais em Geometria na Educação Infantil a fim de verificar quais as que seriam desenvolvidas nessa faixa etária. Quanto aos temas geométricos abordados nas tarefas, eles foram discutidos e escolhidos em conjunto pelas professoras e pelas pesquisadoras tendo em vista os conhecimentos (ou não) das primeiras em relação a eles.

$\mathrm{Na}$ fase da construção e análise a priori foram elaboradas tarefas para o desenvolvimento das Capacidades Espaciais em Geometria a serem desenvolvidas com os alunos desse nível de ensino a partir da seleção previamente realizada. A elaboração das tarefas foi acompanhada por uma discussão teórica e metodológica destinada ao aprofundamento dos aspectos subjacentes à cada uma delas.

$\mathrm{Na}$ experimentação as tarefas elaboradas anteriormente foram aplicadas pelas professoras a fim de verificarmos a adequação do material proposto às possibilidades dos alunos. Em seguida à aplicação, professoras e pesquisadoras se reuniram para apreenderem as percepções iniciais sobre o material e o desenvolvimento da tarefa.

$\mathrm{Na}$ análise a posteriori fizemos a validação do material elaborado e, quando necessário, sua reestruturação para nova aplicação. Nessa fase, foram analisadas pelas pesquisadoras as gravações, realizadas em áudio e vídeo, enfocando os aspectos pertinentes ao ensino e à aprendizagem, bem como as percepções iniciais das professoras coletadas anteriormente.

Após o desenvolvimento das fases anteriores, o material 
foi organizado e publicado, tendo em vista suas contribuições para o trabalho de profissionais que atuam nessa fase de ensino.

\subsection{Dos Materiais e sua Aplicação}

Neste artigo descreveremos três das tarefas que foram desenvolvidas pelas professoras com as crianças nos referidos Centros de Educação Infantil, a primeira das quais foi desenvolvida em uma turma do Infantil I, a segunda, em uma turma do Infantil II e, a terceira, em uma turma do Infantil III.

A turma do Infantil I era acompanhada por três profissionais da educação, uma docente e duas educadoras. A turma era composta por 15 bebês recém- matriculados na escola, dentre os quais havia aqueles que andavam; os que engatinhavam; os que nem andavam, nem engatinhavam.

No infantil II havia 25 alunos, ativos, curiosos e que se comunicavam pouco. Três profissionais da educação acompanhavam esses alunos: a docente e duas educadoras.

O grupo do Infantil III era acompanhado por duas profissionais da educação: a professora e uma educadora. Nessa turma havia 25 crianças, bem ativas, curiosas e que já se comunicavam, embora uma delas, de acordo com a professora, só participasse com seu apoio.

No Infantil I, para as crianças de 6 meses a 1 ano, a tarefa proposta foi denominada "Seguindo o som". O objetivo que a direcionou foi o de proporcionar à criança a possibilidade de explorar o corpo, percebendo as mãos e os pés, a partir do som produzido com sua movimentação.

A tarefa foi proposta considerando que essas crianças já dominavam alguns movimentos corporais e visualizavam o objeto, procurando sua localização, além de perceberem sons. Consideramos que ela envolvia conhecimentos matemáticos ligados ao desenvolvimento das capacidades espaciais por ser nos primeiros meses de vida que o bebê inicia o processo de conhecimento de si e de seu corpo a partir do contato com outros indivíduos e com os objetos a seu redor.

Inicialmente as crianças percebem e distinguem objetos estáticos e em movimento presentes em seu campo de visão e passam a atuar sobre eles e a descobrir novas sensações que estimulam, também, seu interesse por novas descobertas. Um desenvolvimento que parece simples, mas requer um longo e incansável trabalho do sistema nervoso e sensorial.

Experiências como as que propusemos facilitam o desenvolvimento do sistema motor compreendido aqui como a interação existente entre o pensamento, consciente ou não, e o movimento efetuado pelos músculos com a ajuda do sistema nervoso. A interação entre os sistemas muscular e nervoso fazem com que a criança amplie cada vez mais sua noção viso motora e corporal (De Muer \& Staes, 1984).

Um esquema corporal organizado permite que a criança se sinta bem quando seu corpo a obedece, isto é, na medida em que ela passa a ter domínio sobre ele. No entanto, o esquema corporal não é algo que se possa ensinar, visto que ele se organiza pela experimentação da criança. Assim sendo, quanto mais dinâmicas forem as experiências dela com o meio e com os objetos a sua volta, a partir de brincadeiras ou de outras tarefas, maiores serão as possibilidades de enriquecimento psicomotor e de desenvolvimento das noções corporais.

$\mathrm{Na}$ tarefa, apresentada a seguir, a criança irá, a partir do estímulo, procurar pelo som e, com isso, perceber e tocar partes de seu corpo, podendo assim descobrir seu corpo a partir da observação de si mesma.

A proposição para esse grupo foi a utilização de chocalhos a serem colocados nas mãos e/ou nos pés das crianças, partes essas movimentadas pelas professoras para que emitissem som, como observado na Figura 1.

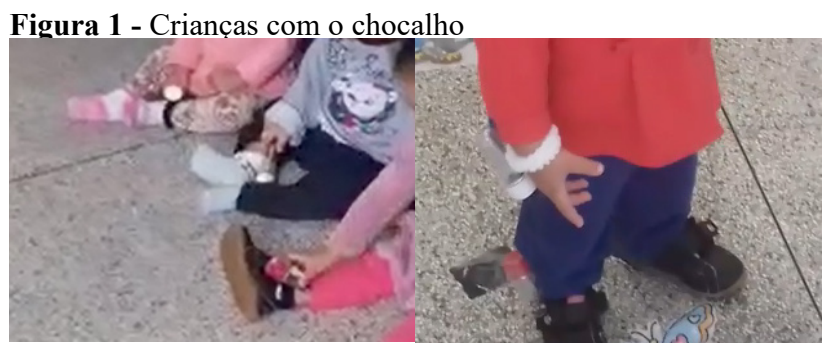

Fonte: Os autores.

As professoras incentivaram as crianças a perceberem que o movimento levava a produção de um som que variava de acordo com a sua intensidade. E as estimulavam a partir de perguntas como: de onde vem esse barulho? Cadê o chocalho que estava aqui?

Como nessa fase do desenvolvimento infantil há o predomínio da linguagem gestual e corporal, perguntas pertinentes podem ser feitas pela professora com o intuito de promover a participação e interação das crianças. Essa proposição considerou que a partir de um estímulo as crianças observassem e percebessem o movimento de suas mãos e pés.

$\mathrm{Na}$ realização da tarefa com esse grupo de crianças, a professora tentou, a princípio, realizar a atividade com todas elas. Contudo, como estavam em diferentes fases de desenvolvimento e em processo de adaptação, a docente achou que deveria reaplicar a tarefa para poder avaliá-la melhor.

Na reaplicação, a docente dividiu a turma em três grupos: o dos bebês que não andam e nem engatinham, os que engatinham, e os que andam. Com essa nova organização foi possível explorar melhor a noção corporal de cada criança do grupo, percebendo suas reações e estimulando cada uma delas segundo suas necessidades.

As educadoras observaram que os materiais utilizados estimularam os bebês que não andavam e nem engatinhavam a procurarem pelo som; os bebês que engatinhavam, a repetiram o movimento para ver o que ocorria; e os que já andavam a observarem o que acontecia quando movimentavam mãos e pés ao mesmo tempo.

Ao final, as profissionais ressaltaram que esta proposta era extremamente pertinente e que a repetiriam em outros momentos por compreenderem que as crianças necessitam de encorajamento e incentivo para perceberem o seu corpo e seus 
movimentos.

No Infantil II, a tarefa proposta para crianças de 2 a 3 anos foi denominada "Em busca de...", cujo objetivo era o de explorar corporalmente um espaço previamente organizado em busca de um objeto que se desejava pegar, explorando os conceitos de direção e distância.

Cada criança era estimulada a realizar um percurso de maneira que fosse mais seguro e conveniente para ela (rolando, em pé, sentado, de joelhos, agachado, etc.). Para tanto selecionamos um material que as motivassem, considerando os movimentos a serem explorados nesse grupo (subir, descer, passar sobre objetos) e o objeto a ser pego ao final do trajeto, necessários para que não se dispersassem durante sua realização.

Essa proposição considerou que a orientação espaçotemporal é a capacidade do indivíduo em situar-se, orientar-se e localizar-se em um espaço determinado, o que, de acordo com Fávero, envolve os "conceitos de direção, sentido (acima, abaixo, frente, atrás, direita, esquerda) e distância (longe, perto)" (2004, p. 28).

Essa proposição considerou que a nossa percepção de mundo se dá a partir orientação espaço-temporal tendo o corpo como referência e envolve conceitos geométricos. No caso da criança, primeiro ela localiza a si própria, em seguida identifica a posição que seu corpo ocupa no espaço e, finalmente, passa a localizar objetos, em uma ação que vai da exteriorização para a interiorização.

Experiências baseadas nas ações que a criança realiza em seu meio a partir de seu corpo lhe possibilitarão compreender o espaço que a cerca permitindo-lhe prever e antecipar suas ações futuras (Le Bouch, 1992). Por esta razão, proposições que estimulam o desenvolvimento corporal são fundamentais para a estruturação de aspectos físicos (relacionados ao seu corpo ou ao ambiente) e para o seu desenvolvimento cognitivo e emocional, além de lhe permitirem aperfeiçoar e refinar seus movimentos adquirindo maior coordenação motora dentro de um espaço e um tempo determinados. Observando a si e os objetos a sua volta ela desenvolve essas noções

A montagem do percurso deveu-se ao fato de este auxiliar o desenvolvimento da expressão corporal (movimento) por provocar estímulos para que as crianças adquiram aos poucos mobilidade e segurança e se arrisquem a percorrer um caminho de forma distinta. A escolha do percurso para nele se movimentarem possibilita às crianças desenvolverem a coordenação motora grossa e o senso de direção e sentido.

Para a aplicação da tarefa escolhemos um local amplo para montar um percurso como apresentado na Figura 2, que tivesse uma entrada e três saídas e dispusemos um bichinho ao final de cada uma delas, pois o tema em desenvolvimento no momento pelas professoras eram os animais.

$\mathrm{Na}$ execução da tarefa, as profissionais incentivavam as crianças a trilharem o percurso de diferentes maneiras: sentado, agachado, em pé, etc. Como nessa fase de desenvolvimento ainda há a dominância da linguagem gestual e corporal sobre a linguagem verbal, as educadoras fizeram perguntas estimulando a participação e interação das crianças (por exemplo: cadê o ursinho? Onde está o cachorro? etc.), de acordo com o objeto escolhido.

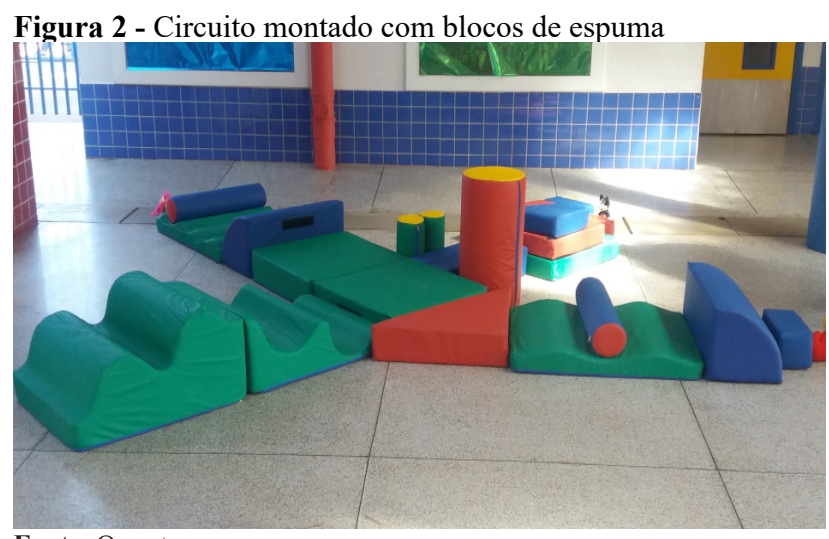

Fonte: Os autores.

As crianças sentiram-se estimuladas a realizarem o percurso pois, além de este ocorrer fora do espaço da sala de aula, utilizava materiais diferenciados e coloridos que chamavam sua atenção e as incitavam a vencer os possíveis obstáculos para sua realização.

$\mathrm{Na}$ avaliação da tarefa as educadoras aprovaram a proposição e destacaram ser ela pertinente para o desenvolvimento das noções corporais, bem como estimulante e desafiadora fazendo com que as crianças vencessem, inclusive, seus medos ao transpor os obstáculos. Sugeriram apenas que sua realização fosse feita com cada uma das crianças para que elas pudessem dar atenção às crianças individualmente durante o percurso.

Para as crianças de 2 a 4 anos, do Infantil III, propusemos o que denominamos de "Por entre a teia", que tinha por objetivo possibilitar a movimentação corporal a partir de comandos em um espaço previamente organizado.

Para a execução dessa tarefa, que envolvia o desenvolvimento de habilidades corporais relacionadas ao espaço, os alunos deveriam conhecer os comandos a serem executados e fazer todo o percurso a partir de um ponto de partida e um de chegada previamente estabelecidos.

Por meio dela a criança desenvolveria a percepção espacial em um processo que se iniciara desde muito cedo, quando a criança, ainda bebê, se deu conta da existência de objetos no espaço. Posteriormente, ao tentar pegar o que via, ela se movimentava e com isso sua compreensão do espaço ia pouco a pouco se ampliando, como demonstrado na tarefa do Infantil II.

A atividade proposta explorava conceitos de direita/ esquerda, por cima/por baixo; para frente/para atrás, quando do deslocamento da criança por entre os fios trançados em uma malha disposta no pátio da escola, conforme as Figuras 3 e 4: 


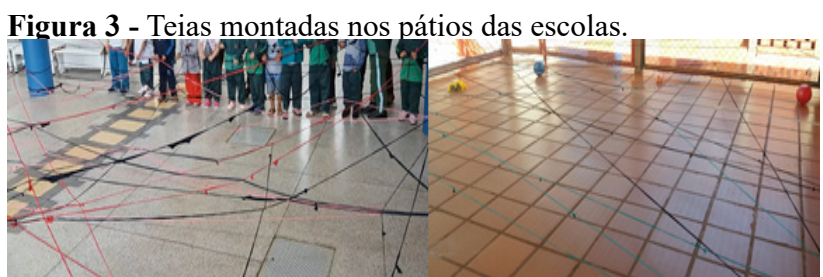

Fonte: Os autores.

Figura 4 - Exploração da teia pelas crianças maiores

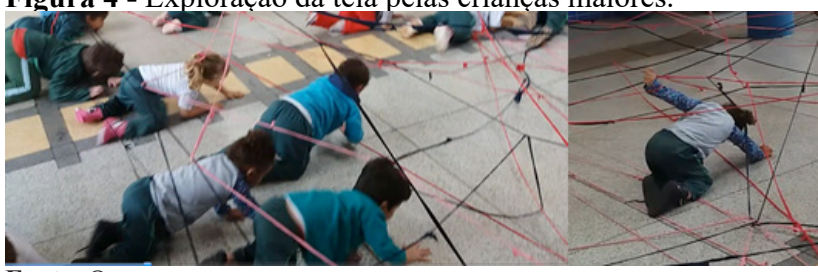

Fonte: Os autores.

Com o espaço organizado antecipadamente e antes que fosse explorado, as educadoras, para inserir as crianças no contexto da tarefa, fizeram uma roda de conversa com elas, estimulando-as, a partir de uma história, a resgatarem a aranha que havia ficado presa em sua teia. Usaram também para essa contextualização a "música da aranha" que fazia parte do repertório do grupo:

A dona aranha subiu pela parede

Veio a chuva forte e a derrubou

Já passou a chuva o sol já vai surgindo

E a dona aranha continua a subir

Ela é teimosa e desobediente

Sobe, sobe, sobe e nunca está contente

A dona aranha subiu pela parede

Veio a chuva forte e a derrubou

Já passou a chuva o sol já vai surgindo

E a dona aranha continua a descer

Ela é teimosa e desobediente

Desce, desce, desce e nunca está contente

A dona aranha subiu pela parede

Veio a chuva forte e a derrubou

Já passou a chuva o sol já vai surgindo

$\mathrm{E}$ a dona aranha continua a subir

Ela é teimosa e desobediente

Sobe, sobe, sobe e nunca está contente

Durante a roda as educadoras reforçaram com as crianças os comandos que as orientariam nesse resgate: se arrastar, saltar, agachar e engatinhar. Foram organizados grupos com dois ou três participantes para facilitar a movimentação deles na teia.

A princípio as crianças percorreram o percurso da forma que achavam mais conveniente e, posteriormente, foram motivadas a fazer o mesmo trajeto explorando os diferentes planos para chegarem ao outro lado da teia. Para a exploração dessa movimentação corporal pelo espaço, as educadoras utilizaram comandos do tipo: "Agora vocês terão que passar pela teia engatinhando", "Agora passarão pulando os fios da teia", "Cuidado, desta vez não poderão deixar a teia tocar no corpo", e assim por diante, explorando dessa forma os diferentes planos do espaço (alto, médio e baixo), ao percorrerem-no em diferentes posições: sentados, agachados, deitados, em pé.

A proposição foi motivadora para as crianças, pois, além de ocorrer fora do espaço da sala de aula, tinha como recurso um material com que estavam tendo contato pela primeira vez. Além disso, a conversa anterior das educadoras com elas criou uma expectativa positiva em relação à brincadeira, de tal modo que não viam a hora de passar por entre os fios da teia.

As educadoras avaliaram positivamente a proposição, destacando ser ela pertinente e estimuladora para o desenvolvimento das noções corporais. Salientaram ainda que não esperavam que, com materiais tão simples, se pudesse fazer um trabalho tão rico enfocando noções de localização, sentido, posição no espaço, que, concordaram, eram fundamentais para essa fase do desenvolvimento infantil.

Essa tarefa foi desenvolvida sem qualquer alteração por não ter havido, por parte das educadoras, necessidade ou pedido de nova aplicação.

\subsection{Do Processo de Formação na Docência}

Acreditamos que a opção metodológica da pesquisa pelas ideias da Engenharia Didática foi a forma de articular o trabalho das pesquisadoras ao das educadoras tendo em vista o processo de ensino e aprendizagem de um conteúdo disciplinar que ainda é pouco conhecido por profissionais que atuam nessa etapa da escolarização.

As fases dessa metodologia contribuíram para a formação do professor na $^{2}$ docência em seus diferentes momentos. Inicialmente, as educadoras definiram, dentro do tema proposto (geometria), quais os conteúdos gostariam que fossem explorados, considerando o Projeto Político Pedagógico da escola e as dificuldades delas em desenvolvê-los.

Quando da apresentação das tarefas às educadoras, elas analisaram a proposição feita pelas pesquisadoras e solicitaram a explicitação dos conteúdos geométricos subjacentes às proposições, no intuito de aprofundarem seus conhecimentos e melhor compreenderem a exploração a ser realizada na execução das tarefas.

Esse foi um momento profícuo para a formação, tanto dessas profissionais que tiveram a oportunidade de discutir suas dificuldades quanto ao ensino, como também para a das pesquisadoras em relação à compreensão daquelas advindas da formação $\mathrm{da}^{3}$ docência, que nem sempre são claras para aqueles que pesquisam o processo de ensino e de aprendizagem.

Outro momento importante dessa formação foi também o

2 A formação na docência refere-se aos processos formativos, institucionalizados ou não, dos quais participam esses profissionais depois de formados, no decorrer de sua atuação profissional (Da Costa, 2017).

3 A formação da docência está relacionada à formação profissional, ou melhor dizendo, à preparação desse profissional para o exercício profissional da docência (Da Costa \& Pavanello, 2017). 
da análise da proposta desenvolvida com o apoio de vídeos e das observações das pesquisadoras. Esses instrumentos possibilitaram às educadoras reverem o encaminhamento na execução das tarefas, a atuação dos seus alunos, o atingimento ou não dos objetivos e o resultado obtido.

O processo de discussão, implícito na metodologia utilizada na pesquisa para a formação na docência, é um instrumento importante e valoroso, pois ampara de modo teórico e prático a atuação dessas profissionais, o que pôde ser constatado, não só quando se disponibilizaram a reaplicar a tarefa em um dos casos, como ao pensarem em outras formas de explorar os conteúdos propostos, adequando-os ao seu perfil docente e ao do seu grupo, contribuindo para sua autonomia profissional.

Embora a proposta metodológica inicial da Engenharia Didática denominada de primeira geração tenha sido inicialmente a pesquisa sobre os entes matemáticos e as dificuldades próprias que apresentam, em outro momento, evoluiu para o que se denominou de segunda geração, na qual os professores deveriam trabalhar com seus alunos, construindo etapas para que esse conhecimento pudesse ser desenvolvido.

Ao utilizarmos a Engenharia Didática como metodologia para essa pesquisa (Pavanello \& Da Costa, 2019), nosso foco foi o de desenvolver esse processo com os professores que dela participaram. Para tal, assumimos a pedagogia dialógica (Freire, 1986) como princípio para a inserção do grupo de professores/educadores na produção e (re) construção da prática pedagógica, o que nos permitiu aliar a teoria à prática, a reflexão à ação e valorizar as diferentes formas de pensar sobre esse conhecimento, movimentos estes permeados pelas interações e o diálogo como elementos fundamentais.

Os requisitos da Engenharia Didática de primeira e segunda geração, foram importantes para a construção e a análise das tarefas, e possibilitaram a ampliação do conhecimento das pesquisadoras, professoras e educadoras sobre cada tema específico, considerando os aspectos subjacentes ao objeto a ser estudado, instituindo dessa forma "os professores como sujeitos de seu processo de aprendizagem, articulando teoria e prática, oportunizando vislumbrar outras possibilidades para a exploração do conhecimento matemático e seu desenvolvimento profissional, o que consideramos aspectos relevantes para a validação do processo empreendido" (Pavanello \& Da Costa, 2019, p. 214) e, ainda, os obstáculos para a apreensão desses conteúdos.

\section{Algumas Considerações}

Embora os resultados tenham sido positivos é necessário ressaltar que, para uma mudança profunda na atuação docente, se faz necessário um tempo para que esses profissionais aprofundem teoricamente os conhecimentos matemáticos abordados, além de refletirem sobre todos os aspectos que envolvem a proposição de tarefas (os saberes do conteúdo, os saberes didáticos e os saberes dos alunos), bem como, e principalmente, contar com apoio, como o dado pelas pesquisadoras, para possibilitar a consolidação das aprendizagens.

Nessa pesquisa, a Engenharia Didática contribuiu metodologicamente para elaboração de produções voltadas para o desenvolvimento das Capacidades Espaciais. Contudo, percebemos a importância da dialogicidade nesse processo, em especial para o nosso foco, que foi o da formação na docência ao instituir os professores como sujeitos de seu processo de aprendizagem e de seu desenvolvimento profissional. Ao articular teoria e prática puderam vislumbrar outras possibilidades para a exploração do conhecimento matemático, o que consideramos aspecto relevante para a validação do processo empreendido.

A interlocução entre pesquisador-professor, professoraluno e pesquisador - aluno, possibilitou a todos se integrarem na pesquisa, o que comprovou a validação dessa proposta, e de ser ela uma forma profícua para a formação na docência.

\section{Referências}

Almouloud, S A, \& Coutinho, C. Q. S. C. (2008). Didática: características e seus usos em trabalhos apresentados no GT-19/ANPEd. REVEMAT, 3 (6), 62-77. doi: https://doi. org/10.5007/1981-1322.2008v3n1p62

Brasil (1997). Secretaria de Educação Fundamental. Parâmetros Curriculares Nacionais: Matemática. Brasília? MS.

Brasil (2017). Ministério da educação e Cultura. Base Nacional Comum Curricular. 2017. Brasília: MS.

Brasil. Lei n. 12796, de 04 de abril de 2013. Altera a Lei no 9.394, de 20 de dezembro de 1996, que estabelece as diretrizes e bases da educação nacional, para dispor sobre a formação dos profissionais da educação e dar outras providências. Brasília: MS.

Brasil. Lei n. 9394/96, de 20 de dezembro de 1996. Estabelece as diretrizes e bases da educação nacional. Brasília, DF. Recuperado de http://www.planalto.gov.br/ccivil_03/leis/ 19394.htm.

Breda, A, Serrazina, L, Menezes, L, Sousa, H. \& Oliveira, P. (2011). Geometria e medida no ensino básico. Brochura de apoio ao Programa de Matemática do Ensino Básico (2007) para o ensino da Geometria e Medida. Portugal: DGIDC.

Da Costa, L. P., \& Pavanello, R. M. (2017). Números e operações: uma discussão da prática docente nos anos iniciais do Ensino Fundamental. Curitiba: CRV.

De Meur, A., \& Staes, L. (1984). Psicomotricidade: educação e reeducação. Rio de Janeiro: Manole.

Faria, A. R. (1998). O desenvolvimento da criança e do adolescente segundo Piaget. São Paulo: Ática.

Fávero, M. T. M. (2004). Desenvolvimento psicomotor e aprendizagem da escrita. Maringá: Universidade Estadual de Maringá.

Freire, P. (1986). Pedagogia do Oprimido. Rio de Janeiro: Paz e Terra.

Kobayashi, M. C. M. (2001). A construção da geometria pela criança. Bauru: EDUSC.

La Taille, Y. (2003). Prefácio. In: Piaget, J. A construção do real na criança. São Paulo: Ática. 
Le Boulch, J. (1992). O desenvolvimento psicomotor: do nascimento até 6 anos. Porto Alegre: Artes Médicas.

Mendes, M. F., \& Delgado, C. C. (2008). Geometria: textos de apoio para educadores de infância. Ministério da Educação de Portugal, Lisboa.

Montoito, R., \& Leivas, J. C. P. (2012). A representação do espaço na criança, segundo Piaget: os processos mentais que a conduzem à formação da noção do espaço euclidiano. Vidya, 32 (2), 21-35.

Oliveira, L. (2005). A construção do espaço segundo Piaget. Sociedade e Natureza, 17, 105-117.

Pacheco, E. D., \& Vasconcelos, P. A. C. (2001) Crise: espaço e representação. Revista Nexos, 4 (7), 103-113.

Pavanello, R. M., Da Costa, L. P. (2019). Formação de professores/educadores para o ensino e a aprendizagem das capacidades espaciais na educação infantil. São Paulo: Educação Matemática Pesquisa, 21 (5), 205-216. doi: https:// doi.org/10.23925/1983-3156.2019v21i5p205-216
Piaget, J. (1999). Seis estudos de Psicologia. Rio de Janeiro: Forense Universitária.

Sena, R. M. M., \& Dorneles, B. V. (2013). Ensino de Geometria: Rumos da Pesquisa (1991-2011). REVEMAT, 8 (1), 138-155. Doi: https://doi.org/10.5007/1981-1322.2013v8n1p138

Van Hiele-Geldof, D. (1957). The didactics of geometry in the lowest class of secondary school. Utrecht: Universidad de Utrecht:

Van Hiele, P. M. (1991). El problema de la comprensión (en conexión con la comprensión de los escolares en el aprendizaje de la geometría). 1957. Utrecht: Universidad de Utrecht.

Van Hiele, P. M. (1986) Structure and insight: a theory of mathematics education. New York: Academic Press. 